\title{
Total oxidant/antioxidant status in jaundiced newborns before and after phototherapy
}

\author{
Estado oxidante/antioxidante total em recém-nascidos ictéricos \\ antes e depois da fototerapia
}

\begin{abstract}
Resumo
Objetivo: Avaliar o efeito da fototerapia no estado oxidante e antioxidante no soro de recém-nascidos a termo com hiperbilirrubinemia.

Método: Trinta e quatro recém-nascidos a termo com idades entre $3 \mathrm{e}$ 10 dias submetidos a fototerapia foram avaliados. 0 estado antioxidante do soro foi determinado pela capacidade antioxidante total e por componentes antioxidantes individuais: vitamina C, ácido úrico, albumina, concentração de tiol e bilirrubina total. $\mathrm{O}$ estado oxidante foi avaliado através do estado oxidante total, índice de estresse oxidativo e componentes oxidantes individuais: malondialdeído e níveis de hidroperóxido lipídico.

Resultados: As concentrações de vitamina C, ácido úrico, bilirrubina total e malondialdeído foram significativamente mais baixas, enquanto que $o$ estado oxidante total, níveis de hidroperóxido lipídico e o índice de estresse oxidativo foram significativamente maiores após a fototerapia $(p<0,05)$. Houve correlações positivas significativas entre a bilirrubina sérica total e a concentração de malondialdeído $(r=0,434, p=0,001)$.

Conclusões: Embora a concentração de malondialdeído tenha diminuído após a fototerapia, esta exerce um efeito negativo sobre as diversas partes do sistema de defesa oxidante/antioxidante em recém-nascidos a termo ictéricos, expondo-os a um possível estresse oxidativo.

J Pediatr (Rio J). 2007;83(4):319-322: Antioxidantes, lactente, malondialdeído, estresse oxidativo, fototerapia.
\end{abstract}

Ali Aycicek', Ozcan Erel²

\section{Introdução}

A fototerapia é a forma de tratamento mais amplamente usada contra a hiperbilirrubinemia não-conjugada ${ }^{1,2}$. Sua natureza não-invasiva, alta disponibilidade, baixo custo e baixa ocorrência de efeitos colaterais praticamente levaram à pressuposição inicial de que é inócua ${ }^{3}$. A possibilidade de que talvez isso não seja verdade foi aventada em várias publicações recentes, que demonstraram que a fototerapia é um estresse fotodinâmico e que ela pode induzir a peroxidação lipídica. A crescente valorização do papel causal do dano oxi-

\author{
Abstract \\ Objective: To assess the effect of phototherapy on serum oxidant and \\ antioxidant status in hyperbilirubinemic full-term newborns.
}

Method: Thirty-four full-term infants from 3 to 10 days of age exposed to phototherapy were studied. The serum antioxidant status was assessed by measuring the total antioxidant capacity (TAC) and individual antioxidant components: vitamin C, uric acid, albumin, thiol contents and total bilirubin. The oxidant status was assessed by determining the total oxidant status (TOS), oxidative stress index (OSI) and individual oxidant components: malondialdehyde (MDA), and lipid hydroperoxide levels.

Results: Vitamin C, uric acid, total bilirubin and MDA concentration were significantly lower, whereas serum TOS, lipid hydroperoxide and OSI levels were significantly higher after phototherapy $(p<0.05)$. There were significant positive correlations between serum total bilirubin and MDA $(r=0.434, p=0.001)$.

Conclusions: Although the MDA level was reduced after phototherapy, phototherapy has a negative impact on numerous parts of the oxidant/antioxidant defense system in jaundiced full-term newborns, exposing them to potential oxidative stress.

J Pediatr (Rio J). 2007;83(4):319-322: Antioxidants, infant, malondialdehyde, oxidative stress, phototherapy.

dativo e da peroxidação lipídica no desenvolvimento de muitas doenças graves do recém-nascido vem dando grande importância à peroxidação lipídica e às suas possíveis causas ${ }^{4}$.

Os radicais livres e os metabólitos relacionados vêm recebendo grande atenção nos últimos anos ${ }^{5}$. Eles se originam principalmente do oxigênio e são gerados no corpo por vários sistemas endógenos, exposição a diferentes condições físicoquímicas ou estados fisiopatológicos. Os radicais livres podem modificar os lipídeos, proteínas e DNA, tendo sido

1. MD. Pediatrician, Department of Pediatrics, Children's Hospital at Sanliurfa, Sanliurfa, Turkey.

2. MD. Professor, Department of Clinical Biochemistry, Harran University, Medical Faculty, Research Hospital, Sanliurfa, Turkey.

Como citar este artigo: Aycicek A, Erel O. Total oxidant/antioxidant status in jaundiced newborns before and after phototherapy. $\mathrm{J}$ Pediatr (Rio J). 2007;83(4):319-322.

Artigo submetido em 08.05.06, aceito em 12.03.07.

doi 10.2223/JPED.1645 
envolvidos na lesão pulmonar por oxigênio, hemorragia intraventricular, retinopatia da prematuridade, lesão de isquemia/reperfusão caracterizada por enterocolite necrotizante, dano ao sistema nervoso central pós-asfixia e necrose tubular aguda ${ }^{6,7}$. As reações da bilirrubina envolvendo os radicais livres ou produtos tóxicos da redução do oxigênio encontram-se bem documentadas: a bilirrubina não-conjugada capta o oxigênio no estado singlet com alta eficiência, reage com os ânions do superóxido e radicais de peroxil, servindo como substrato redutor das peroxidases na presença de peróxido de hidrogênio ou hidroperóxidos orgânicos ${ }^{8,9}$.

Formulamos a hipótese de que um fator importante no mecanismo do estresse oxidativo nos recém-nascidos a termo com hiperbilirrubinemia submetidos a fototerapia nos primeiros dias de vida seria o aumento do estresse oxidativo em relação aos antioxidantes. Esse desequilíbrio seria afetado pelo estresse oxidativo exacerbado, número reduzido de antioxidantes, ou uma combinação de ambos. O objetivo deste estudo foi testar a validade dessa hipótese através da determinação dos papéis relativos do estresse oxidativo e da reduzida atividade antioxidante total.

\section{Métodos}

Cinqüenta e sete recém-nascidos a termo com idades entre 3 e 10 dias, nascidos de parto vaginal e admitidos ao Sanliurfa Children's Hospital por causa de hiperbilirrubinemia indireta clinicamente significativa foram avaliados neste estudo. Todos os lactentes encontravam-se em amamentação e não possuíam nenhum fator etiológico de hiperbilirrubinemia. Os lactentes com má formação congênita grave, diabetes materno, asfixia ao nascimento, sepse ou hiperbilirrubinemia do tipo hemolítica devido à incompatibilidade de grupo sanguíneo ( $\mathrm{Rh}$ ou $\mathrm{ABO}$ ); aqueles que receberam fototerapia intensiva; aqueles em que o nível de bilirrubina sérica total aumentou em mais de $5 \mathrm{mg} / \mathrm{dL}$ por dia ou foi maior que $20 \mathrm{mg} / \mathrm{dL}$ nas primeiras 24 horas do nascimento; e aqueles com sinais e sintomas sugestivos de doença grave foram excluídos do estudo. A hiperbilirrubinemia indireta clinicamente importante foi definida como aquela presente em lactentes com uma concentração de bilirrubina sérica total maior que $13 \mathrm{mg} / \mathrm{dL}^{10}$. Os recém-nascidos desnudos, exceto aqueles que usavam fraldas e protetores oculares, foram colocados em uma incubadora com um sistema de fototerapia que consistia em seis lâmpadas fluorescentes brancas (Philips TL 20W/54) localizadas $40 \mathrm{~cm}$ acima da incubadora. A energia da unidade fototerápica, medida através de um fotômetro padrão (Light Meter VF, Minolta, Japão), correspondeu a $12-16 \mu \mathrm{W} / \mathrm{cm}^{2} / \mathrm{nm}$. Todos os bebês foram submetidos a fototerapia contínua durante 48 horas, exceto durante a amamentação, limpeza e amostragem. Esse período de tempo foi escolhido a fim de permitir a amostragem simultaneamente aos testes rotineiros de bilirrubina, evitando assim a coleta de sangue apenas para fins do estudo. Este estudo foi aprovado pelo Comitê local de Ética. Um consentimento informado foi obtido dos pais para a participação dos recém-nascidos no estudo.

\section{Métodos analíticos}

Amostras de sangue foram coletadas a partir de uma veia periférica para determinar a bilirrubina total, bilirrubina direta e as concentrações antioxidantes e oxidantes antes da fototerapia. Uma segunda amostra de sangue foi coletada de 49 lactentes após 48 horas. Essas amostras foram centrifugadas a 1500 x g por 10 minutos em até 20 minutos depois da coleta. As amostras séricas foram armazenadas a $-80^{\circ} \mathrm{C} \mathrm{e}$ analisadas em até 2 meses.

A capacidade antioxidante total (CAT) foi determinada pelo método de Erel $^{11,12}$, que se baseia no embranquecimento da cor característica de um radical catiônico mais estável de 2,2'-azino-bis (3-etilbenzotiazolina-6-ácido sulfônico) (ABTS) pelos antioxidantes. Os resultados foram expressos em mmol equivalente de Trolox./L. O tiol sérico (total - grupo $\mathrm{SH}$ ) foi medido pelo ácido ditio nitrobenzóico $(\text { DTNB })^{13}$. A concentração da vitamina $C$ foi determinada pelo método FRASC ${ }^{14}$. O ácido úrico, albumina e bilirrubina total, que são antioxidantes individuais do soro, foram medidos através de kits comerciais (Abbott). O estado oxidante total (EOT) no soro foi determinado pelo método de Erel $^{15}$, que é baseado na oxidação do íon ferroso para íon férrico na presença de várias espécies oxidativas em meio ácido e na determinação do íon férrico pelo laranja de xilenol. Os resultados foram expressos em $\mu \mathrm{mol} \mathrm{H}_{2} \mathrm{O}_{2} / \mathrm{L}$. Os métodos CAT e EOT de Erel são colorimétricos e automatizados e a precisão desse ensaio é excelente - menor que $3 \%{ }^{13,16}$. O malondialdeído (MDA) sérico foi medido através de um método fluorométrico ${ }^{17,18}$. As concentrações de hidroperóxido lipídico no soro também foram medidas usando o método automatizado xilenol-férrico laranja ${ }^{19}$. A proporção entre EOT e CAT foi considerada como o índice de estresse oxidativo (IEO $^{20,21}$. Para realizar o cálculo, a unidade do CAT foi trocada de mmol equivalente de Trolox / $L$ para $\mu$ mol equivalente de Trolox $/ L$, e o valor do IEO foi calculado da seguinte forma: IEO $=[(E O T, \mu \mathrm{mol} / \mathrm{L}) /(\mathrm{CAT}, \mu \mathrm{mol}$ equivalente de Trolox /L) /100].

\section{Análise estatística}

A análise estatística dos dados foi realizada através do Statistical Package for the Social Sciences, versão 11.0, para Windows (SPSS, Inc). Para comparar as amostras de sangue coletadas antes e depois da fototerapia, foi usado o teste $t$ de Student para amostras pareadas, utilizando-se um intervalo de confiança de $95 \%$. As associações bivariadas entre as variáveis contínuas foram determinadas pelo teste de correlação de Pearson. Valores $p$ menores que 0,05 foram considerados estatisticamente significativos.

\section{Resultados}

A média de idade dos lactentes foi de $6 \pm 3$ dias, comprimento médio de $50 \pm 3,8 \mathrm{~cm}$, peso corporal médio igual a $3,1 \pm 1,4 \mathrm{~kg}$, perímetro cefálico médio de $36,2 \pm 1,9 \mathrm{~cm}$, sendo 29 do sexo masculino e 28 do sexo feminino. Os parâmetros antioxidantes/oxidantes séricos antes e depois da fototerapia são mostrados na Tabela 1. O CAT sérico, concentração de tiol e níveis de albumina não se alteraram após a fototerapia. 
Tabela 1 - Comparação dos parâmetros séricos oxidantes e antioxidantes antes e depois da fototerapia em recém-nascidos ictéricos. Os dados são expressos como média \pm DP

\begin{tabular}{|c|c|c|c|}
\hline & $\begin{array}{c}\text { Antes } \\
\text { da fototerapia } \\
(n=57)\end{array}$ & $\begin{array}{c}\text { Após } \\
\text { a fototerapia } \\
(n=49)\end{array}$ & p* \\
\hline \multicolumn{4}{|l|}{ CAT (mmol equiv. de } \\
\hline Trolox /L) & $1,54 \pm 0,31$ & $1,48 \pm 0,13$ & 0,281 \\
\hline Total - grupo SH (mmol/L) & $0,42 \pm 0,01$ & $0,43 \pm 0,01$ & 0,165 \\
\hline Vitamina C (mg/dL) & $2,1 \pm 1,3$ & $1,3 \pm 0,6$ & 0,029 \\
\hline Ácido úrico (mg/dL) & $5,0 \pm 2,7$ & $3,7 \pm 1,4$ & 0,027 \\
\hline Albumina (mg/dL) & $3,8 \pm 0,5$ & $3,9 \pm 0,5$ & 0,580 \\
\hline Bilirrubina total ( $\mu \mathrm{mol} / \mathrm{L})$ & $17,1 \pm 2,5$ & $13,8 \pm 2,3$ & $<0,001$ \\
\hline \multicolumn{4}{|l|}{ EOT ( $\mu \mathrm{mol}$ equiv.de } \\
\hline $\left.\mathrm{H}_{2} \mathrm{O}_{2} / \mathrm{L}\right)$ & $11,34 \pm 5,9$ & $16,34 \pm 7,4$ & 0,002 \\
\hline $\operatorname{MDA}(\mu \mathrm{mol} / \mathrm{L})$ & $2,46 \pm 0,36$ & $1,98 \pm 0,33$ & $<0,001$ \\
\hline $\begin{array}{l}\text { Hidroperóxido lipídico } \\
\left(\mu \mathrm{mol} \mathrm{H}_{2} \mathrm{O}_{2} / \mathrm{L}\right)\end{array}$ & $6,11 \pm 2$ & $7,37 \pm 2,8$ & 0,025 \\
\hline IEO (unidade arbitrária) & $0,07 \pm 0,03$ & $0,11 \pm 0,05$ & 0,002 \\
\hline
\end{tabular}

CAT = capacidade antioxidante total $;$ EOT = estado oxidante total; IEO = índice de estresse oxidativo; MDA = malondialdeído.

* Teste $t$ para amostras pareadas.

As concentrações séricas de vitamina C, ácido úrico, bilirrubina total e MDA foram significativamente mais baixas após a fototerapia que antes da mesma $(p<0,05)$. Por outro lado, os níveis séricos de EOT, hidroperóxido lipídico e IEO foram significativamente mais altos após a fototerapia que antes da mesma $(p<0,05)$. Houve correlações positivas significativas entre a bilirrubina sérica total e MDA $(r=0,434, p=0,001)$. Além disso, não houve correlação entre a bilirrubina total e outros parâmetros.

\section{Discussão}

No presente estudo, as concentrações de vitamina C e de ácido úrico, que são antioxidantes amplamente conhecidos, foram significativamente mais baixas após a fototerapia que antes da mesma; em contrapartida, os níveis de EOT, hidroperóxido lipídico e IEO foram significativamente maiores após a fototerapia que antes da mesma. É interessante notar que o MDA, um produto final da peroxidação lipídica e um marcador oxidante, apresentou níveis baixos após a fototerapia. Houve também uma correlação positiva significativa entre os níveis de MDA e bilirrubina total. Todos os estudos publicados discorrem sobre os efeitos oxidantes da fototerapia, especialmente do peróxido lipídico (que é uma substância reativa do ácido tiobarbitúrico), e das atividades das enzimas antioxidantes, mas não sobre a capacidade sérica antioxidante total não-enzimática ${ }^{22-27}$. Este é o primeiro relato que mostra a associação entre esses parâmetros séricos oxidantes/antioxidantes em lactentes a termo com hiperbilirrubinemia não-hemolítica submetidos a fototerapia.

Em um ser humano saudável, a formação e inativação das espécies reativas de oxigênio são contrabalanceadas a um nível em que os compostos podem exercer seu papel fisiológico sem nenhum efeito tóxico. Esse equilíbrio pode ser instável no período neonatal após rápidas alterações na concentração de oxigênio nos tecidos, mecanismo antioxidante imaturo e mudanças consideráveis nos antioxidantes durante o desenvolvimento neonatal. Essa deterioração é particularmente evidente na presença de estresse oxidativo, como por exemplo, fototerapia ${ }^{4}$.

Embora a fototerapia seja amplamente usada no tratamento da hiperbilirrubinemia neonatal, há uma preocupação em relação à possibilidade de dano fotodinâmico ao tecido ${ }^{28}$. A exposição de lactentes à fototerapia na presença de um sensibilizador (bilirrubina) resultou em lesão oxidativa à membrana eritrocitária caracterizada por um aumento significativo nas concentrações de produtos da peroxidação lipídica na membrana e por hemólise ${ }^{29}$. Outro estudo relatou que a fototerapia na presença de bilirrubina levou a uma queda acentuada na atividade da ATPase e a uma maior susceptibilidade à peroxidação lipídica nos eritrócitos neonatais ${ }^{4}$. Nosso estudo revelou que houve aumentos importantes nos hidroperóxidos lipídicos e no EOT séricos com a fototerapia em recém-nascidos ictéricos.

As concentrações plasmáticas de MDA em recém-nascidos com icterícia não-hemolítica foram significativamente maiores que em lactentes saudáveis ${ }^{22,23}$. Ozture et al. relataram que as concentrações de MDA diminuíram consideravelmente após a fototerapia em relação ao período que a precedeu, e que não houve correlação significativa entre as concentrações plasmáticas de MDA e de bilirrubina antes e depois da fototerapia ${ }^{23}$. Yigit et al. descreveram que não houve correlação significativa entre os níveis de MDA e de bilirrubina ${ }^{22}$. Esses autores também demonstraram que tanto os níveis de bilirrubina como os de MDA eram elevados em lactentes ictéricos e que ambos os parâmetros diminuíram após a fototerapia; todavia, eles não encontraram uma correlação significativa entre os parâmetros opostos dos oxidantes/antioxidantes. Os resultados de nosso estudo confirmaram esses achados; todavia, também investigamos os níveis séricos de EOT, hidroperóxido lipídico e IEO. Em nosso estudo, as concentrações séricas de MDA diminuíram consideravelmente após a fototerapia e houve uma correlação significativa entre as concentrações plasmáticas de MDA e de bilirrubina antes e após a fototerapia $(r=0,434, p=$ $0,001)$. Esses resultados sugerem que o estresse oxidativo não foi causado pela fototerapia. Contudo, os níveis de EOT, hidroperóxido lipídico e IEO aumentaram significativamente após a fototerapia. A causa aparente desses dados conflitantes está no fato de que a determinação do MDA não é um método específico para a peroxidação lipídica, e de que a mesma é influenciada positivamente pela bilirrubina e algumas estruturas do aldeído ${ }^{15}$. O MDA é um produto final da peroxidação lipídica e o hidroperóxido lipídico, que é o nosso parâmetro de peroxidação lipídica, é um indicador precoce da cadeia de oxidação de lipídeos, sendo que o último método não interfere em outras estruturas.

Estudos anteriores investigaram o efeito da fototerapia na atividade enzimática antioxidante eritrocitária (glutationa peroxidase, superóxido dismutase, etc.) em lactentes ictéricos. Investigamos a capacidade sérica antioxidante total 
não-enzimática e os antioxidantes individuais. Bohles et al. descreveram uma redução significativa no ácido úrico sérico durante a fototerapia ${ }^{30}$. De um lado, a diminuição na concentração de ácido úrico é discutida como um efeito da fotodecomposição direta, e de outro, como um efeito inibidor da deficiência de riboflavina sobre a formação do ácido úrico. Descobrimos que os níveis de CAT não foram significativamente alterados pela fototerapia, mas que as concentrações de vitamina $\mathrm{C}$ e de ácido úrico diminuíram consideravelmente. No entanto, os níveis de CAT não foram reduzidos e o equilíbrio oxidante/antioxidante mudou significativamente para o lado oxidante, já que outros indicadores do estado oxidante, tais como os níveis de hidroperóxidos lipídicos, EOT e IEO, aumentaram significativamente nos lactentes ictéricos submetidos a fototerapia.

A conclusão é de que a fototerapia tem um efeito negativo em várias partes do sistema oxidante/antioxidante em recém-nascidos com hiperbilirrubinemia, expondo-os a um possível estresse oxidativo.

\section{Referências}

1. Porter ML, Dennis BL. Hyperbilirubinemia in the term newborn. Am Fam Physician. 2002;65:599-606.

2. Tan KL. Phototherapy for neonatal jaundice. Acta Paediatr. 1996;85:277-9.

3. Tan KL. Phototherapy for neonatal jaundice. Clin Perinatol. 1991;18:423-39.

4. Gathwala G, Sharma S. Oxidative stress, phototherapy and the neonate. Indian J Pediatr. 2000;67:805-8.

5. Devasagayam TP, Tilak JC, Boloor KK, Sane KS, Ghaskadbi SS, Lele RD. Free radicals and antioxidants in human health: current status and future prospects. J Assoc Physicians India. 2004; 52:794-804.

6. Warner BB, Wispe JR. Free radical-mediated diseases in pediatrics. Semin Perinatol. 1992;16:47-57.

7. Halliwell B. Free radicals, antioxidants, and human disease: curiosity, cause, or consequence. Lancet. 1994;344:721-4.

8. Stocker R, Ames BN. Potential role of conjugated bilirubin and copper in the metabolism of lipid peroxides in bile. Proc Natl Acad Sci USA. 1987;84:8130-4

9. Stocker R, Glazer AN, Ames BN. Antioxidant activity of albuminbound bilirubin. Proc Natl Acad Sci USA. 1987;84:5918-22.

10. Newman TB, Maisels MJ. Evaluation and treatment of jaundice in the term newborn: a kinder, gentler approach. Pediatrics. 1992;89(5 Pt 1):809-18.

11. Erel O. A novel automated direct measurement method for total antioxidant capacity using a new generation, more stable ABTS radical cation. Clin Biochem. 2004;37:277-85.

12. Erel O. A novel automated method to measure total antioxidant response against potent free radical reactions. Clin Biochem. 2004;37:112-9.

13. Hu ML, Louie S, Cross CE, Motchnik P, Halliwell B. Antioxidant protection against hydrochlorous acid in human plasma. J Lab Clin Med. 1993;121:257-62.
14. Chung WY, Chung JK, Szeto YT, Tomlinson B, Benzie IF. Plasma ascorbic acid: measurement, stability and clinical utility revisited. Clin Biochem. 2001;34:623-7.

15. Erel O. A new automated colorimetric method for measuring total oxidant status. Clin Biochem. 2005;38:1103-11.

16. Ahn MR, Kumazawa S, Hamasaka T, Bang KS, Nakayama T. Antioxidant activity and constituents of propolis collected in various areas of Korea. J Agric Food Chem. 2004;52:7286-92.

17. Kamal AA, Gomaa A, el Khafif M, Hammad AS. Plasma lipid peroxides among workers exposed to silica or asbestos dusts. Environ Res. 1989;49:173-80.

18. Erel O, Kocyigit A, Avci S, Aktepe N, Bulut V. Oxidative stress and antioxidative status of plasma and erythrocytes in patients with vivax malaria. Clin Biochem. 1997;30:631-9.

19. Arab K, Steghens JP. Plasma lipid hydroperoxides measurement by an automated xylenol orange method. Anal Biochem. 2004;325:158-63.

20. Harma M, Harma M, Erel O. Oxidative stress in women with preeclampsia. Am J Obstet Gynecol. 2005;192:656-7.

21. Aycicek A, Erel O, Kocyigit A. Decreased total antioxidant capacity and increased oxidative stress in passive smoker infants and their mothers. Pediatr Int. 2005;47:635-9.

22. Yigit S, Yurdakok M, Kilic K, Oran O, Erdem G, Tekinalp G. Serum malondialdehyde concentration in babies with hyperbilirubinaemia. Arch Dis Child Fetal Neonatal Ed. 1999;80:F235-7.

23. Ozture H, Duman M, Duman N, Ozkan H. How phototherapy affects the relation between serum bilirubin and plasma malondialdehyde in neonates. Arch Dis Child Fetal Neonatal Ed. 2000;82:F171.

24. Turgut M, Basaran O, Cekmen M, Karatas F, Kurt A, Aygun AD. Oxidant and antioxidant levels in preterm newborns with idiopathic hyperbilirubinaemia. J Paediatr Child Health. 2004;40:633-7.

25. Akisu M, Coker C, Tuzun S, Yilmaz D, Kultursay N. Serum malondialdehyde levels in preterm and full-term infants undergoing phototherapy. Acta Paediatr. 1998;87:605-6.

26. Akisu M, Yilmaz D, Tuzun S, Kultursay N. Antioxidant defense systems in newborns undergoing phototherapy. Indian J Pediatr. 1999;66:651-5.

27. Ostrea EM Jr., Cepeda EE, Fleury CA, Balun JE. Red cell membrane lipid peroxidation and hemolysis secondary to phototherapy. Acta Paediatr Scand. 1985;74:378-81.

28. McDonagh AF. The role of singlet oxygen in bilirubin photo-oxidation. Biochem Biophys Res Commun. 1971;44:1306-11.

29. Vreman HJ, Wong RJ, Stevenson DK. Phototherapy: current methods and future directions. Semin Perinatol. 2004;28:326-33.

30. Bohles $H$, Schnall B. [The effect of phototherapy on serum uric acid (author's transl)]. Klin Padiatr 1981;193:308-10.

Correspondência:

Ali Aycicek

Sanliurfa Cocuk Hastaliklari Hastanesi

63200 Sanliurfa - Turquia

Tel.: +904143131144

Fax: +904143130470

E-mail: ayciceka@hotmail.com; ali_aycicek@yahoo.com.tr 